\title{
COMPARISON OF THREE HERBAL PLANTS FOR BEST FREE RADICAL SCAVENGING ACTIVITY
}

\author{
RADHA PALANISWAMY1, PALGHAT RAGHUNATHAN PADMA²
}

\author{
${ }^{1}$ Dept. of Biotechnology, Dr. NGP Arts and Science College, Coimbatore 641048, India, ${ }^{2}$ Dept. of Biochemistry, Biotechnology and \\ Bioinformatics, Avinashilingam University for Women, Coimbatore 641043, India
} Email: palaniswamyradha@gmail.com

Received: 27 Dec 2016, Revised and Accepted: 20 Mar 2017

\section{BSTRACT}

Objective: Excessive production of reactive oxygen species leads to oxidative stress. Antioxidants can prevent or retard the oxidation caused by free radicals and sufficient intake of antioxidants is supposed to protect against diseases. Candidate play

Methods: The leaf extracts of these plants were exposed to a battery of free radical scavenging assays like DPPH, ABTS, hydrogen peroxide, superoxide and nitric oxide to determine the free radical scavenging activity.

Results: It was observed that the Majoranahortensis leaves in methanolic extract showed maximum scavenging activity.

Conclusion: Several plants with free radical scavenging activity have been identified, where Majoranahortensis is one such leave.

Keywords: Artemisia pallens, Majoranahortensis, Cymbopoganflexuosus, Free radical scavengers, Oxidative stress

(C) 2016 The Authors. Published by Innovare Academic Sciences Pvt Ltd. This is an open access article under the CC BY license (http://creativecommons.org/licenses/by/4.0/] DOI: http://dx.doi.org/10.22159/ijcpr.2017v9i3.18898

\section{INTRODUCTION}

Herbal medicines have contributed immensely to the world of medicine in various forms. Due to the lack of documentation, today herbal medicine is unable to outgrow the various other forms of medicines [1].

However, current research in pharmacology and herbal medicine has paved way for considering the traditional plants for its medicinal value. Medicinalplants are an important alternative to extract natural antioxidant compounds todelay or prevent the oxidative damage caused by ROS [2]. Artemisia pallens (A. pallens). Majoranahortensis (M. hortensis), Cymbopoganflexuosus (C. flexuosus) are three aromatic herbal plants grown perennially in India and are considered for the present study.

A. pallens commonly called davana, native to India, belongs to the family of Asteraceae. Several previous studies have reported that it is used as antifungal, antiviral, and antimalarial agent. It is used to treat diabetes mellitus, rheumatoid arthritis and lupus nephritis [3]. The second plant, $M$. hortensis belongs to family Lamiaceae, finds its place in religious ceremonies and has several uses in therapeutic remedies, insecticidal effect due to terpenes, and carries several traditional uses [4].

The third herb is $C$. flexuosus, belongs to family Poaceae, rich in essential oils, which enables it to find a place in perfumery, cosmetics and pharmaceuticals. It is known to cure headache, anxiety, and gives soothing effects [5]. In the present study, the free radical scavenging activity of the three aromatic herbs has been studied and compared.

Free radicals are small, diffusible molecules which contain an unpaired electron. It damages the multiple molecules due to its nature of single free radical initiation chain [6]. Free radicals can be scavenged and protect the cells against oxidative stress which can inhibit the cells from various devastating effects in its life cycle [7]. The objective of the study: A set of three aromatic plants (Artemisia pallens, Majoranahortensis, Cymbopoganflexuosus) were chosen to elucidate the best free radical scavenging property from the three different extracts (alcohol, methanol and chloroform).

\section{MATERIALS AND METHODS}

All the three leaf samples were obtained from pots grown in the campus which were tender in nature. Organic solvent extracts of alcohol, methanol and chloroform were used for the evaporation.

The residue was dissolved in DMSO (dimethyl sulphoxide) at 20 $\mathrm{mg} / 5 \mu \mathrm{l}$. The scavenging effect of all the three leaf samples in 3 different solvent extracts were subjected to a battery of assay like DPPH (1,1' diphenyl 1-2-picryl hydrazil), ABTS (2,2' azinobis-3-ethyl benzthiazoline-6-sulphonic acid), hydrogen peroxide, superoxide and nitric oxide radicals.

DPPH Spectrophotometric Assay: The scavenging ability towards the stable free radical DPPH was measured by the method proposed by Mensor et al. [8]. ABTS scavenging effects: The ABTS radical cation decolorizing assay was done according to the Shirwaiker et al. [9].

Protocol. Hydrogen peroxide scavenging effect: The ability of the leaf extracts to scavenge hydrogen peroxide was assessed by the method of Ruch et al. [10].

Superoxide Scavenging Activity: Superoxide scavenging ability was determined by the Winterbourn et al. [11] assay. Nitric oxide scavenging activity: The extent of inhibition of nitric oxide radical generation in vitro was followed as per the method reported by Green et al. [12].

\section{RESULTS}

In DPPH, ABTS and hydrogen peroxide assay, the percentage of scavenging was calculated. In DPPH assay, M. hortensis showed the maximum scavenging activity compared to other two. Among the different organic solvent extracts, methanol showed better activity than alcohol or chloroform. Similar trend was observed in ABTS and hydrogen peroxide assay and the values were plotted at wavelength $517 \mathrm{~nm}$.

The percent inhibition of free radical formation was maximum in methanolic extract of $M$. hortensis sample compared to the others in both superoxide and nitric oxide assays. 
DPPH

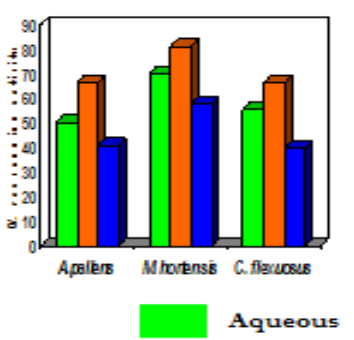

ABT 5

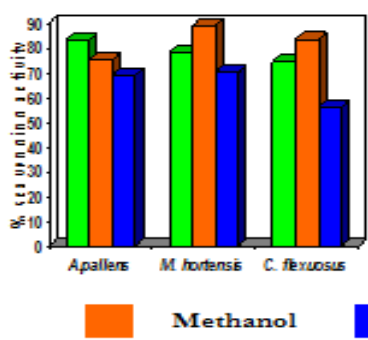

$\mathrm{H}_{2} \mathrm{O} 2$

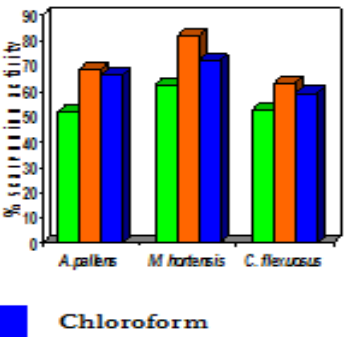

Fig. 1: Free radical scavenging activities of DPPH, ABT, $\mathrm{H}_{2} \mathrm{O}_{2}$

SO

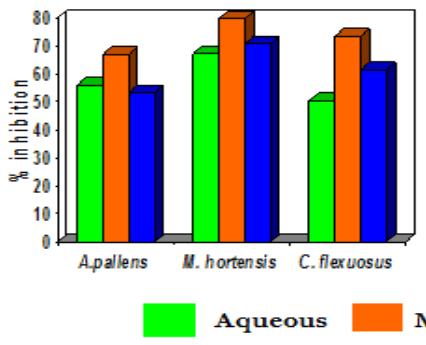

NO

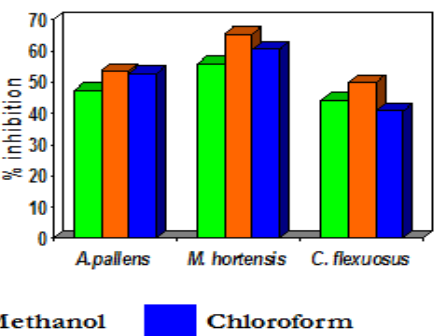

Fig. 2: Percent inhibition by SO and NO.

\section{DISCUSSION}

Our results were supported by other researches where a methanol extract of Conyzacanadensis exhibited good DPPH radical scavenging effect than its petroleum ether and ethyl acetate extracts [13]. It was reported that Lippiagraveolens, and Phoenix theophrasti [14] also exhibited strong DPPH scavenging activities. Bacosides from Bacopamonnieri also showed excellent free radical scavenging activity by ABTS assay [15]. The ABTS assayis based on the antioxidant capacity of the samples to prevent the oxidation of ABTS to ABTS++ radicalcation [16]. Our results are similar with the methanolic extract of both leaves and rhizome of Curcuma amada, which exhibited the maximum scavenging activity of DPPH and ABTS [17].

Hydrogen peroxide is an important reactive oxygen species due to its ability to penetrate into the biological membrane [18]. Methanolic and ethyl acetate extracts of the medicinally valuable Chionanthusvirginicus scavenged H2O2 to a significant extent [19]. The ethanol extract of the leaves of Solanumsurattense was capable of scavenging $\mathrm{H}_{2} \mathrm{O}_{2}$ inadose-dependent manner [20], which correlates with our results.

The hexane, chloroform, ethyl acetate, methanol and water extracts of bark and leaves of Cassia siamea and Cassia javanica [21] showed significant inhibition of superoxide radical formation. Lopez et al. [22] have demonstrated that the aqueous and methanol extracts from Melissa officinalis were active in inhibiting SO• production in a xanthine-xanthine oxidase system.

Nitric oxide is an inorganic reactive nitrogen species synthesized in organisms by different NO synthase isoforms. Nitric oxide is an unstable free radical involved in many biological processes which is associated with several diseases. It reacts with oxygen to produce stable product nitrate and nitrite through intermediates and high concentration of nitric oxide can be toxic and inhibition of over production is an important goal [Wang]. In another study conducted on the methanolic extracts of four different varieties of rice bran, namely Vasumathi, Yamini, Jyothi and Njavara, the highest nitric oxide scavenging activity was observed in Njavara [23]. From these results there is adequate evidence to support the current study on the free radical scavenging profile of the 3 aromatic herbs.

\section{CONCLUSION}

The above results indicated that the $M$. hortensis leaf extract showed the maximum scavenging activity compared to the others and among the three extracts, the methanolic extract proved to be better than the others. Hence, further study can be carried out with the methanolic extract of the $M$. hortensis leaf extracts which is an aromatic, perennial herb. The constituents or the secondary metabolites present in the extract can be evaluated to understand the cause of its augmented scavenging activity compared with the other herbal aromatic extracts of $A$. pallens and $C$. flexuosus.

\section{ACKNOWLEDGEMENT}

The authors are grateful to the WoS-A (Women Scientist Scheme A) scheme, Department of Science and Technology, New Delhi, for their financial support.

\section{CONFLICT OF INTERESTS}

Declare none

\section{REFERENCES}

1. Akinmoladun AC, Ibukun EO, Dan-Ologe IA. Phytochemical constituents and antioxidant properties ofextracts from the leaves of Chromolaenaodorata. Sci Res Essay 2007;2:191-4.

2. Athukorala Y, Nam K, Jeon Y. Antiproliferative and antioxidant properties of an enzymatic hydrolysate from brown alga Ecklonia cava. Food Chem Toxicol 2006;44:1065-74.

3. Ruikar AD, Khatiwora E, Ghayal NA, Misar AV, Mujumdar AM, Puanik VG, et al. Studies on aerial parts of Artemisia pallens wall for phenol, flavonoid and evaluation of antioxidant activity. J Pharm Bioallied Sci 2011;3:302-5.

4. El Moursi A, Talaat IM, Balbaa LK. The physiological effect of some antioxidant polyphenols on sweet marjoram (Majroanahortensis) plants. Nusantra Biosci 2012;4:11-5.

5. Sarma A, Sarma H, Sarma TC, Handique AK. Screening of essential oil obtained from inflorescence of lemongrass (Cymbopogonflexuosus) accessions. Indian J Nat Prod Resour 2011;2:236-41.

6. Adhikari S, Priyadarsini IK, Mukherjee T. Physico-chemical studies on the evaluation of the antioxidant activity of herbal 
extracts and active principles of some Indian medicinal plants. J Clin Biochem Nutr 2007;40:174-83.

7. Lobo V, Patil A, Phatak A, Chandra N. Free radicals, antioxidants and functional foods: impact on human health. Pharmacogn Rev 2010;4:118-26.

8. Mensor CC, Menezes FS, Leitao GG, Reis AS, Dos Santos TC, Coube CS, et al. Screening of Brazilian plant extracts for antioxidant activity by the use of DPPH free radical method. Phytother Res 2001;15:127-30.

9. Shirwaikar A, Rajendran K, Kumar CD. In vitro antioxidant studies of Annona squamosaLinn. leaves. Indian J Exp Biol 2004;42:803-7.

10. Ruch RJ, Cheng S, Klaunig JE. Prevention of cytotoxicity and inhibition of intercellular communication by antioxidant catechins isolated from Chinese green tea. Carcinogen 1998;10:1003-8.

11. Winterbourne CC, Hawkins RW, Brain M, Carrell RW. The estimation of red cell superoxide dismutase activity. J Lab Clin Med 1975;85:337-41.

12. Green LC, Wagner DA, Glogowski J, Skipper PL, Wishnok JS, Tannenbaum SR. Analysis of nitrate, nitrite and (15N), nitrate in a biological fluid. Anal Biochem 1982;126:131-8.

13. Hayet E, Maha M, Samia A, Ali MM, Souhir B, Abderaouf K, et al. Antibacterial, antioxidant and cytotoxic activities of extracts of Conyzacanadensis (L.) Cronquist growing in Tunisia. Med Chem Res 2009;18:447-54.

14. Liolios CC, Sotiroudis GT, Chinou I. Fatty acids, sterols, phenols and antioxidant activity of Phoenix theophrasti fruits growing in Crete, Greece. Plant Foods Hum Nutr 2009;64:52-61.

15. Mohana M, Padma PR. Free radical scavenging activity of bacoside fraction from Bacopamonnieri. Int J Curr Pharm Res 2016;8:61-4.
16. Gao H, Shupe TF, Eberhardt TL, Hse CY. Antioxidant activity of extracts from the wood and bark of Port Orford cedar. J Wood Sci 2007;53:147-52.

17. Sivaprabha J, Sumathi S, Dharani B, Padma PR. Radical scavenging activity of leaves and rhizomes of Curcuma amada. Int J Pharm Res Dev 2011;3:167-74.

18. Chen Y, Miao Y, Huang L, Li J, Sun H, Zhao Y, et al. Antioxidant activities of saponins extracted from Radix trichosanthis: an in vivo and in-vitro evaluation. BMC Complementary Altern Med 2014;14:86-93.

19. Gulcin I, Elias R, Gepdiremen A, Boyer L, Koksal E. A comparative study on the antioxidant activity of fringe tree (Chionanthusrirgincus L.) extract. Afr J Biotech 2007;6:410-8.

20. Kaur P, Arora S. Superoxide anion radical scavenging activity of Cassia siamea and Cassia javanica. Med Chem Res 2009;20:9-15.

21. Lopez V, Martın S, Gomez-Serranillos MP, Carretero ME, Jager AK, Calvo MI. Neuroprotective and neurological properties of Melissa officinalis. Neurochem Res 2009;34:1955-61.

22. Wang BS, Chen JH, Liang YC, Duh PD. Effects of Welsh onion on oxidation of low-density lipoprotein and nitric oxide production in macrophage cell line RAW 264.7. Food Chem 2005;91:147.

23. Rao AS, Reddy SG, Babu PP, Reddy AR. The antioxidant and antiproliferative activities of methanolic extracts from Njavara rice bran. BMC Complementary Altern Med 2011;10:4-9.

\section{How to cite this article}

- Radha Palaniswamy, Palghat Raghunathan Padma. Comparison of three herbal plants for best free radical scavenging activity. Int J Curr Pharm Res 2017;9(3):62-64. 